\title{
Beta-glucan contamination of pharmaceutical products: How much should we accept?
}

\author{
Claire Barton ${ }^{1}$ - Kim Vigor ${ }^{2} \cdot$ Robert Scott $^{2} \cdot$ Paul Jones $^{1} \cdot$ Heike Lentfer $^{2}$ • \\ Heather J. Bax ${ }^{3,4,5} \cdot$ Debra H. Josephs ${ }^{3,4,5} \cdot$ Sophia N. Karagiannis ${ }^{3,4} \cdot$ James F. Spicer $^{5}$
}

Received: 8 March 2016 / Accepted: 20 July 2016 / Published online: 29 July 2016

(C) The Author(s) 2016. This article is published with open access at Springerlink.com

\begin{abstract}
Beta-glucans are large polysaccharides produced by a range of prokaryotic and eukaryotic organisms. They have potential immunostimulatory properties and have been used with therapeutic intent as anti-microbial and anti-tumour agents. A range of other potentially beneficial effects have been described, and oral forms of beta-glucans are widely available over-the-counter and online. Parenteral formulations are popular in parts of Asia and are the subject of ongoing trials, worldwide. Beta-glucans are also potential contaminants of pharmaceutical products, and high levels have been described in some blood products. However, little is known about the clinical effects of such contamination, considerable uncertainty exists over the level at which immunostimulation may occur, and there are no guidelines available on acceptable levels. We encountered beta-glucan contamination of one of our products, and we suspect that
\end{abstract}

Claire Barton

claire.barton@cancer.org.uk

1 Cancer Research UK Centre for Drug Development, Cancer Research UK, Angel Building, 407 St John Street, London EC1V 4AD, UK

2 Biotherapeutics Development Unit, Cancer Research UK, South Mimms, Hertfordshire EN6 3LD, UK

3 Division of Genetics and Molecular Medicine, Faculty of Life Sciences and Medicine, St. John's Institute of Dermatology, King's College London, 9th Floor, Guy's Tower Wing, Guy's Hospital, London SE1 9RT, UK

4 NIHR Biomedical Research Centre at Guy's and St. Thomas's Hospitals, King's College London, 9th Floor, Guy's Tower Wing, Guy's Hospital, London SE1 9RT, UK

5 Division of Cancer Studies, Department of Research Oncology, Faculty of Life Sciences and Medicine, King's College London, 3rd Floor Bermondsey Wing, Guy's Hospital, Great Maze Pond, London SE1 9RT, UK others may encounter similar issues since the origin of beta-glucan contamination includes commonly used filters and solutions applied in the manufacture of biotherapeutic agents. It is likely that regulators will increasingly enquire about beta-glucan levels in pharmaceutical products, especially those with an immunomodulatory mechanism of action. Here, we review the literature on beta-glucans in pharmaceutical products and propose an acceptable level for therapeutic agents for parenteral use.

Keywords Beta-glucan - Lentinan · Biotherapeutics · Antibodies $\cdot$ Cancer $\cdot$ Immunostimulation

$\begin{array}{ll}\text { Abbreviations } \\ \text { CI } & \text { Confidence intervals } \\ \text { CR3 } & \text { Complement receptor-3 } \\ \text { CRUK } & \text { Cancer Research UK } \\ \text { IFN } & \text { Interferon } \\ \text { IKB } & \text { Inhibitor of } \kappa \text { B kinase } \\ \text { IL } & \text { Interleukin } \\ \text { MIF } & \text { Migration inhibitory factor } \\ \text { NIHR } & \text { National Institute for Health Research } \\ \text { NSCLC } & \text { Non-small cell lung dancer } \\ \text { PGE2 } & \text { Prostaglandin-E2 } \\ \text { RR } & \text { Relative risk } \\ \text { TIMP } & \text { Tissue inhibitor of metalloproteinase } \\ \text { TME } & \text { Tumour microenvironment }\end{array}$

\section{Introduction}

Beta-glucans are polysaccharides of D-glucose monomers linked by (1-3) beta-glycosidic bonds (see Fig. 1 for an example). They are structurally diverse, and differences in the length and branching of side chains result in differences 


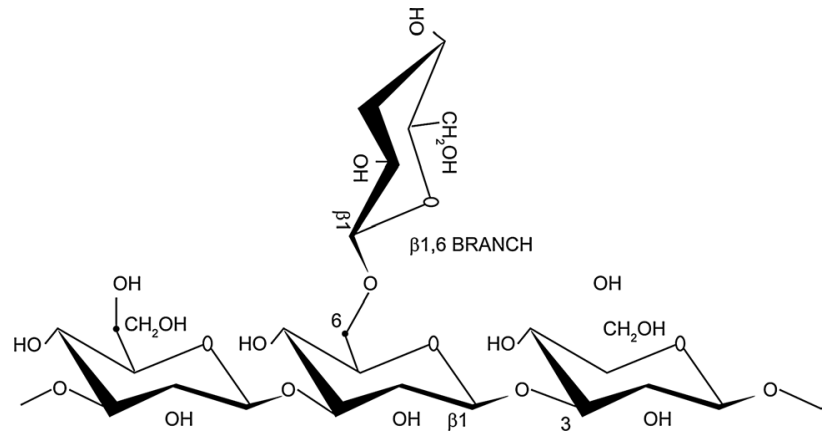

Fig. 1 Beta-glucans are polysaccharides composed of D-glucose monomers linked by (1-3) beta-glycosidic bonds. A simple linear 1,3 glycosidic chain with a single 1,6 glycosidic branch is illustrated here, but there are many variations (figure derived from Chan et al. [23], originally published in BioMed Central)

in solubility and biological activity (reviewed [1]). Betaglucans are found in the cell walls of a wide range of prokaryotic and eukaryotic organisms, including yeast, fungi, seaweeds and cereals. They are a potential contaminant in pharmaceutical products, originating from cellulose-based filters and other raw materials used in pharmaceutical processing. Beta-glucans are similar to endotoxins in that they are large polysaccharides that can elicit an inflammatory response. Currently, endotoxins are strictly regulated in terms of maximum permitted levels in pharmaceutical products (ICH Q6A and Q6B Specifications, 1999 $[2,3])$. Specifications are also in place for residual proteins and polypeptides in biological products (ICH Q6B Specifications, 1999 [3]), but there is no such guidance available for beta-glucans [4].

Recently we encountered contamination of a biotherapeutic agent by beta-glucans. The product, MOv18 IgE (an IgE directed towards the tumour-associated antigen, folate receptor-alpha), was manufactured at the Cancer Research UK, Biotherapeutics Unit for a phase I clinical trial (CRUKD/14/001; EudraCT number 2014-000070-19) in patients with advanced malignancies, in the United Kingdom (UK). This is the first trial in which a monoclonal IgE is administered to patients with therapeutic intent.

Extensive non-clinical testing indicates that anaphylactic reactions should not occur with MOv18 IgE [5], and all patients in the trial are scheduled to undergo intradermal testing prior to every infusion to avoid administration of MOv18 IgE to any patient at risk of an anaphylactic reaction due to MOv18 IgE itself or to any other constituent. However, infusion-related reactions due to non-specific cytokine release could occur with MOv18 IgE, as commonly seen with therapeutic $\operatorname{IgG}$ antibodies and other biological agents. At the time of occurrence, such reactions could be confused with anaphylaxis. However, evaluation of serum tryptase levels should enable infusion-related reactions due to non-specific cytokine release to be distinguished retrospectively from anaphylaxis due to mast cell or basophil degranulation triggered by MOv18 IgE. Since infusion-type reactions have been reported with rapid intravenous (i.v.) administration of beta-glucans [6, 7], it was considered particularly important to ensure that levels of beta-glucans in the MOv18 IgE preparation were sufficiently low for there to be no adverse reactions attributable to co-administration of beta-glucans in the clinical trial. Beta-glucans have also been reported to have immunostimulatory properties when administered orally or parenterally, and we also wished to avoid any immunostimulatory effect from co-administered beta-glucans which could cause confusion with the anticipated immunologically mediated antitumour activity of MOv18 IgE [8-12].

The source of contamination of MOv18 IgE was extensively investigated and turned out to be commonly used cellulose filters and sucrose-containing solutions. Measures were taken to reduce the levels of contamination through additional downstream processing and extra washing steps. This led to an almost 10-fold reduction in beta-glucan levels, which now lie within the range found in commercially available antibodies used in oncology [13]. Subsequent batches of MOv18 IgE contained around $3 \mathrm{ng} / \mathrm{mg}$ of beta-glucans. Based on levels of beta-glucans detected in the bulk drug substance from development, scale up and clinical batches of MOv18 IgE, and a review of the literature on the possible clinical implications of beta-glucans administration, we submitted an amendment to the Investigational Medicinal Product Dossier for our product to include a specification of $10 \mathrm{ng} / \mathrm{mg}$ for beta-glucan contamination. With this level of contamination, we estimated that up to $500 \mathrm{ng}$ of beta-glucans could potentially be delivered on a single occasion to an individual patient in the trial. A $500 \mathrm{ng}$ dose could result in plasma levels of around $100 \mathrm{pg} / \mathrm{mL}$ assuming distribution only to the circulating volume and no clearance. This specification was accepted by the UK Medicines and Healthcare Products Regulatory Agency. From our review of the literature, this appears to be the first time a specification limit for beta-glucans, approved by a regulatory authority, has been reported.

With cellulose-based filters and sucrose-based formulation buffers commonly used in the manufacture of biotherapeutic products, we suspect that other scientists and clinicians working on the research and development of biotherapeutics for use in patients with cancer and other diseases will encounter beta-glucan contamination. Furthermore, regulatory authorities are now more likely to enquire about beta-glucans in biotherapeutic products. This issue may be particularly important in oncology with the advent of new therapeutics, including monoclonal antibodies and other biological agents, which have a variety of complex immunomodulatory mechanisms of action. 
The measures taken to identify the source of contamination and to reduce the levels of beta-glucans contamination in our product are described in detail in a separate publication [13]. Here, we provide an overview of the safety and tolerability of beta-glucans as contaminants of other therapeutic agents, and as a therapeutic agent in its own right, based on a review of the literature. After a brief review of insoluble/particulate beta-glucans (generally orally administered), this overview concentrates on soluble forms since these are most relevant to contamination of biotherapeutic agents, such as monoclonal antibodies and their derivatives, which are given parenterally.

\section{Insoluble (particulate) beta-glucans}

Oral forms of beta-glucans are widely available over-thecounter as oat bran and bran-based products such as breakfast cereals, cereal bars and drinks. These are promoted mainly for their clinically proven cholesterol-lowering properties ([14] and reviewed in [15]), which are complemented by favourable effects on glucose metabolism [16] and possibly other cardiovascular risk factors (reviewed in [17]). There is also evidence that orally administered beta-glucans have beneficial anti-inflammatory and proapoptotic effects in inflammatory bowel disease and colitisassociated colon cancer [18].

Beta-glucan supplements are also readily available online as tablets, capsules and other oral formulations (see for example, Amazon [19] or the Web MD website [20]). These forms of beta-glucans are more frequently derived from sources other than oat bran (such as yeast or fungi) and tend to be promoted as immune stimulants, protecting against microbial infections and cancer.

Topical beta-glucans are also used in cosmetics and as "cosmeceuticals", for improving skin health and appearance, based on non-clinical studies demonstrating beneficial effects of beta-glucans on wound healing, inflammation, ageing (antioxidant and anti-wrinkle activity) and moisturisation (reviewed in [21]).

\section{Immunological effects of beta-glucans}

\section{Effects on host immune defence}

The immunomodulatory properties of beta-glucans have been the subject of considerable scientific study in the Western world for several decades. Non-clinical studies indicate that beta-glucans activate innate immunity as well as adaptive immunity, modulating both humoral and cellmediated immune responses. Beta-glucans act on several immune receptors including Dectin-1 (considered the main receptor for beta-glucans [22]), complement receptor-3 (CR3) and toll-like receptors 2 and 6 (TLR-2/6) (reviewed in [23-26]). Beta-glucans have been found to increase the anti-microbial activity of mononuclear cells and neutrophils, to enhance the functional activity of macrophages, to stimulate the proliferation of monocytes and macrophages and to stimulate the production of proinflammatory molecules such as complement components, interleukin (IL)$1 \alpha / \beta$, TNF- $\alpha$, IL-2, interferon (IFN)- $\gamma$, eicosanoids, IL-4 and IL-10. Consistent with these findings, beta-glucans have also been shown to protect against or ameliorate the effects of bacterial and other infections in animal models (reviewed in [23-26]). The broad-ranging immunological effects of beta-glucans and the epidemiological associations between environmental beta-glucans exposure and respiratory allergies have also led to interest in their use in the prevention or treatment of allergic diseases. The ability of beta-glucans to rebalance a dysregulated $\mathrm{Th} 1 / \mathrm{Th} 2$ equilibrium is thought to be beneficial in these conditions (reviewed in [27]).

It is thought that the immunological effects of orally administered beta-glucans are essentially the same as those of parenterally administered beta-glucans. Orally administered beta-glucans are absorbed through the gastrointestinal tract and taken up by tissue-resident macrophages. Here, they are fragmented, transported to the bone marrow and reticuloendothelial system and eventually released and taken up by other immune cells, leading to various immunological effects (reviewed in [23]). On the basis of these features, particulate beta-glucans have been evaluated as potential vaccines for invasive fungal diseases (reviewed in [28]) and beta-glucans particles have been proposed as a delivery system for oral vaccines, acting as both carrier and adjuvant [29].

\section{Potential anti-cancer effects}

It has been suggested that beta-glucans, administered alone, in combination with monoclonal antibodies, or as adjuvants alongside vaccines or other types of immunotherapy, could help reduce cancer growth. Beta-glucans may act either within tumour microenvironments (TMEs) or systemically, by activating or recruiting immune effector cells into tumours or by augmenting adaptive immune responses triggered by concurrent immunotherapy.

Beta-glucan administration has been reported to influence polarisation of tumour-associated macrophages away from an immunosuppressive and towards an activatory and tumouricidal phenotype (M1). This polarisation is thought to be mediated by engaging the cell surface C-type lectin receptor Dectin-1 and triggering the spleen tyrosine kinase (Syk)-Card9-Erk pathway via the ITAM domain [30]. This may result in production of 
inflammatory cytokines by macrophages and antigenpresenting cells, and tumour growth restriction through enhanced phagocytosis, antigen presentation and induction of Th1 and CTL responses. In one study, beta-glucan administration to mammary tumour-bearing mice triggered IL-12 production by macrophages which led to a switch from IL-4- to IFN- $\gamma$-producing Th1 cells [31]. Another study reported reversal of MDSC immunosuppressive phenotypes in response to particulate beta-glucan treatment. The beta-glucan promoted mature $\mathrm{CD} 11 \mathrm{c}^{+}$ F4/80 $0^{+}$Ly6C ${ }^{\text {low }}$ MDSCs via a Dectin-1/NF-kB-dependent pathway, and this was associated with enhanced infiltration of dendritic cells, macrophages and CTLs in tumours [32].

Well-known immunosuppressive forces in TMEs can profoundly impair the maturation and antigen-presenting functions of DCs. TME-associated inflammation promotes IL-10- and TGF $\beta$ - secreting DC phenotypes, which supports accumulation of regulatory $\mathrm{T}$ cells. These effects have been shown to be reversed upon administration of beta-glucans and are accompanied by a reduction in regulatory $\mathrm{T}$ cells and enhanced tumour infiltration by mature DCs, macrophages and granulocytes in mouse models of cancer [33, 34]. Early data suggest potential enhancement of PD-L1 expression on mouse peritoneal macrophages by microparticulate beta-glucan, which could have a negative impact on $\mathrm{T}$ cell survival and activation [35]. However, potential effects in relation to cancer-associated immune surveillance, immunomodulation or treatment with anti-PD-1 checkpoint inhibitors are yet to be explored.

The potential administration of beta-glucans in combination with antibodies, vaccines and other immunotherapeutic or chemotherapeutic agents has been investigated in pre-clinical studies. Monoclonal antibodies, especially those which function via complement activation, have shown improved efficacy in animal models of cancer when co-administered with beta-glucans. These effects, most likely due to the ability of beta-glucans to bind complement receptor-3 (CR3) and to promote antibody-mediated complement activation against cancer cells, were also associated with recruitment of tumouricidal granulocytes to tumour sites [36, 37]. Consistent with these findings, encouraging efficacy was reported in a non-randomised phase II clinical study, in which the anti-EGFR complement-activating antibody cetuximab was administered in combination with a soluble $\beta-1,3 / 1,6$-glucan to patients with KRAS-mutant/EGFR signalling-resistant colorectal carcinomas [38]. Results of phase I/II trials of beta-glucans in combination with other immunotherapeutic agents also indicate good tolerability with promising signs of antitumour activity in patients with chronic lymphocytic leukaemia and neuroblastoma [39, 40].

\section{Dose-response considerations}

Generally, non-clinical and clinical studies of the immunological effects of beta-glucans have not been designed to establish a dose-response relationship between betaglucans and the effect of interest at low doses/concentrations, or to define the lowest dose/concentration at which immunological effects occur. However, based on a range of nonclinical studies, it seems unlikely that clinically significant immunological effects would occur with serum levels of $100 \mathrm{pg} / \mathrm{mL}$ or lower. One in vitro study showed that exposure to $100 \mathrm{pg} / \mathrm{mL}$ of beta-glucans for $48 \mathrm{~h}$ stimulated the production of IL-17 by dendritic cells in mixed lymphocyte reaction assays, but stimulation was most marked at $1 \mathrm{ng} / \mathrm{mL}$ (10 times higher than $100 \mathrm{pg} / \mathrm{mL}$ ) and there was no effect on IFN- $\gamma$ or IL- 5 production at concentrations up to $100 \mu \mathrm{g} / \mathrm{mL}$ [41]. In a separate study, some induction of IL- $1 \beta$ and IL-12 by macrophages was detected at beta-glucans concentrations as low as $10 \mathrm{ng} / \mathrm{mL}(100$ times higher than $100 \mathrm{pg} / \mathrm{mL}$ ) [42]. However, production of these cytokines was much greater at higher concentrations, and for macrophages to produce TNF- $\alpha$ or IFN- $\gamma$, a beta-glucans concentration of at least $0.1 \mu \mathrm{g} / \mathrm{mL}$ (100 ng/ $\mathrm{mL}$ ) was required. In another study, an enhanced oxidative burst response and microbial killing by peripheral blood mononuclear cells were detected at beta-glucans levels of $100 \mathrm{ng} / \mathrm{mL}(0.1 \mu \mathrm{g} / \mathrm{mL})$ or greater, but stimulation of the NF-kB-like DNA-binding protein by beta-glucans only occurred at concentrations of $370 \mathrm{ng} / \mathrm{mL}(0.37 \mu \mathrm{g} / \mathrm{mL})$ and above [43].

A range of immunological effects have been demonstrated with beta-glucans concentrations between 0.2 and $10 \mu \mathrm{g} / \mathrm{mL}$, including dendritic cell activation and maturation [44-46], neutrophil chemotaxis [47], histamine release from basophils [48] and tumour cell killing by polymorphonuclear leucocytes [49]. For example, in one study, as little as $3 \mu \mathrm{g} / \mathrm{mL}$ of beta-glucans induced the production of intracellular and membrane-associated IL-1, but induction of secreted IL-1 required $25 \mu \mathrm{g} / \mathrm{mL}$, with $50 \mu \mathrm{g} / \mathrm{mL}$ yielding maximal responses. Production of prostaglandin-E2 (PGE2) by glucan-activated human monocytes occurred at concentrations of as low as $12.5 \mu \mathrm{g} / \mathrm{mL}$ but plateaued at $25 \mu \mathrm{g} / \mathrm{mL}$ [45]. Examples of in vitro studies in which the immunological effects of beta-glucans have been evaluated at low concentrations are summarised in Table 1. Of note, many of the studies which looked for a dose-response effect also looked at duration of exposure. To see immunological effects at lower concentrations, relatively prolonged exposure to beta-glucans (12-72 h) may have been required.

Of note, in vitro studies in which the direct anti-tumour effects of beta-glucans have been evaluated suggest that higher concentrations of beta-glucans are required than 


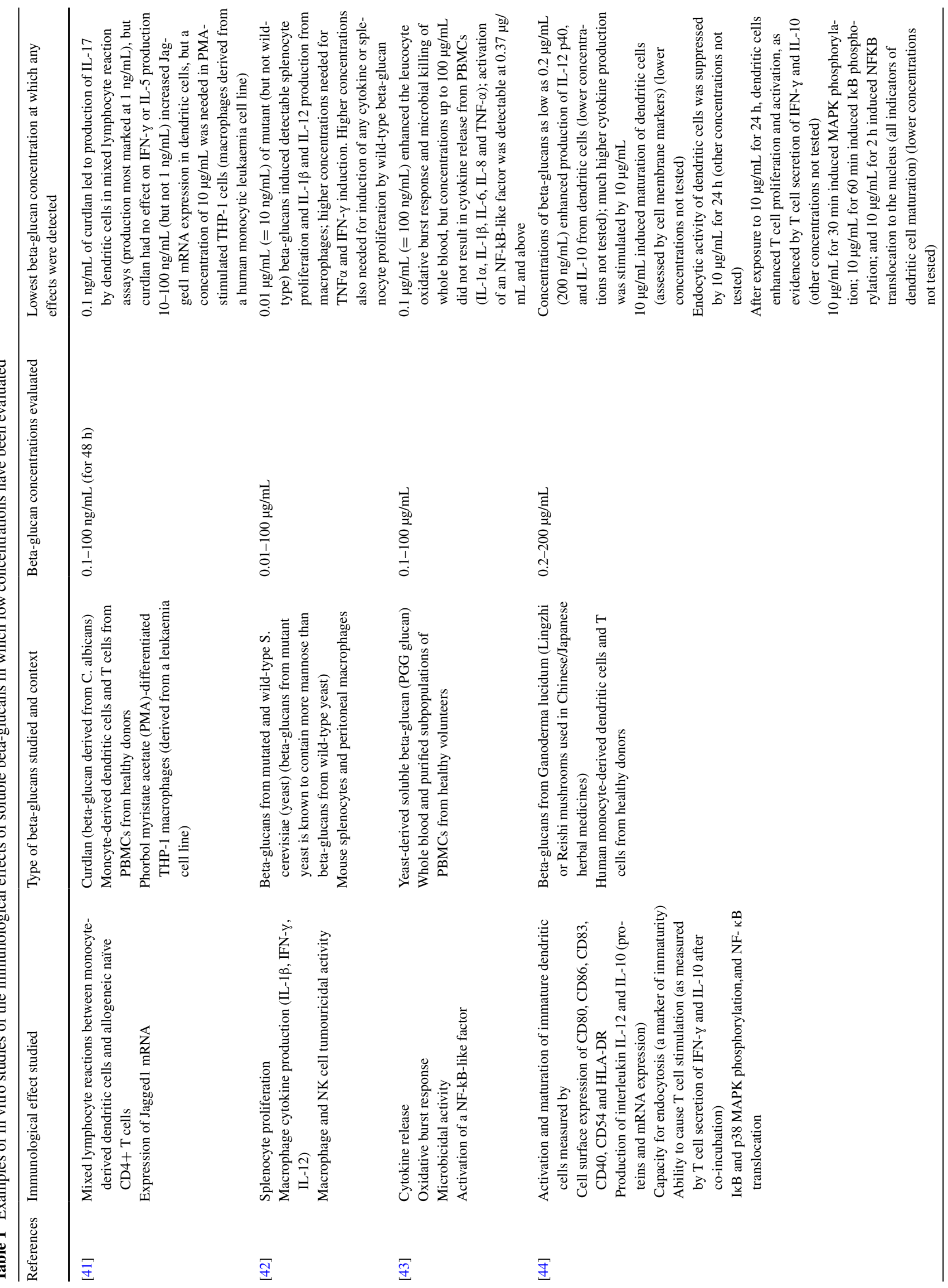




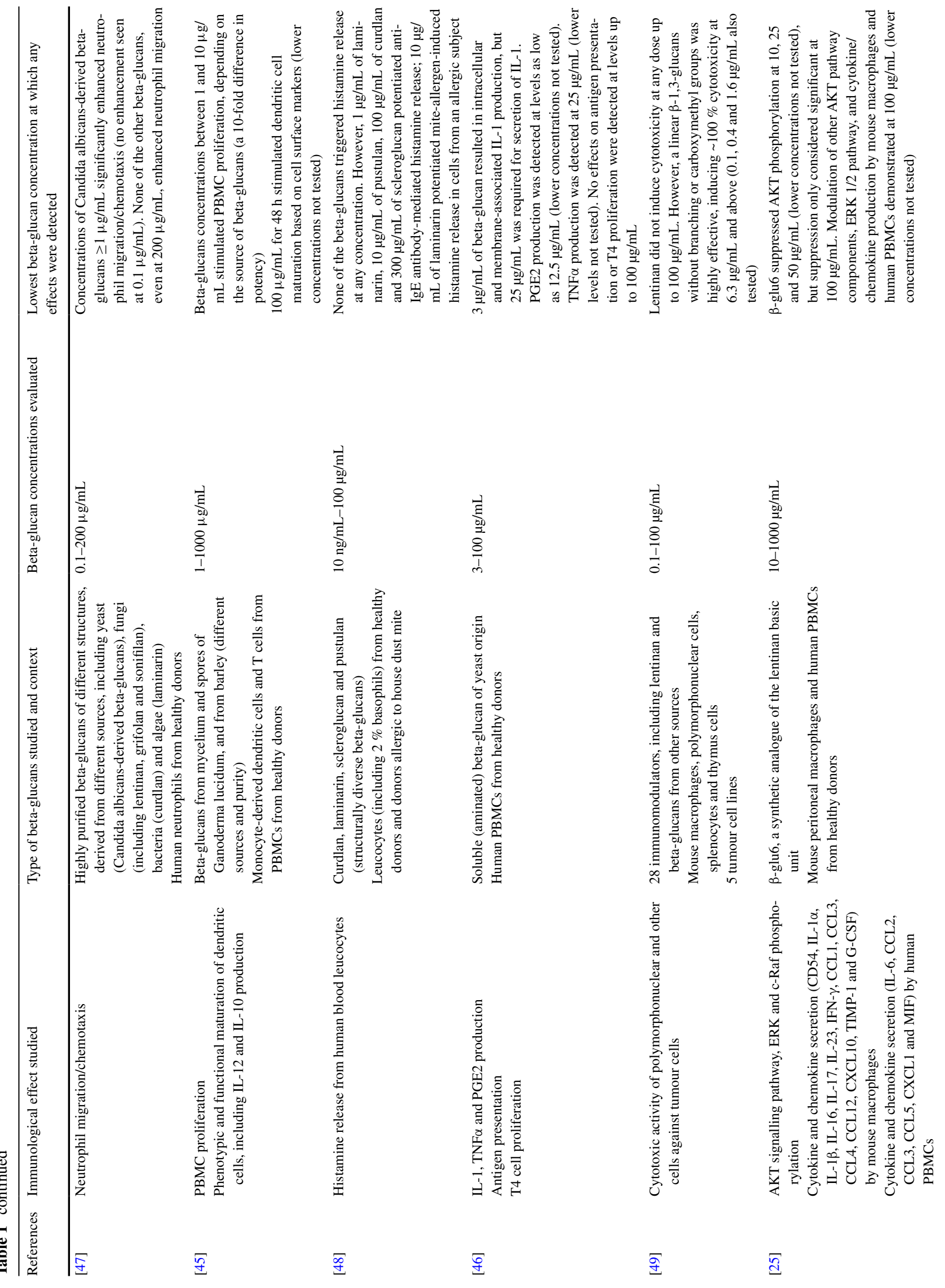


those needed for immune modulation. For example, in an in vitro cytotoxicity analysis, beta-glucans concentrations up to $100 \mu \mathrm{g} / \mathrm{mL}$ did not directly affect the growth of colon 26-M3.1 cells [42]. In other studies, the proliferation of B16-F10 melanoma cells was reduced by $51 \%$ after $48 \mathrm{~h}$ exposure to $750 \mu \mathrm{g} / \mathrm{mL}$ of beta-glucans [52]; proliferation of the gastric cancer cell line SGC-7901 was reduced in a dose-dependent manner at concentrations between 125 and $1000 \mu \mathrm{g} / \mathrm{mL}$, with around $50 \%$ inhibition with $400 \mu \mathrm{g} /$ $\mathrm{mL}$ [53]; and proliferation of MCF-7 breast cancer cells was reduced in a dose-dependent manner at concentrations between 12.5 and $400 \mu \mathrm{g} / \mathrm{mL}$, with $50 \%$ inhibition at 400 $\mu \mathrm{g} / \mathrm{mL}[54]$.

\section{Non-clinical safety data for parenteral beta-glucans}

Most publications in the English/Western literature which describe administration of beta-glucans with therapeutic intent for malignant or other diseases (notably human immunodeficiency virus [HIV] infections) involve oral administration of beta-glucans. However, in the 1980s and more recently, soluble forms of beta-glucans were developed for parenteral administration (see for example, [55-57]). These formulations underwent pre-clinical testing, and data have been published in the English literature (see for example [55, 58-60]). In non-clinical safety studies, mice, rats, guinea pigs and rabbits received a single i.v. injection of soluble beta-glucans in doses ranging from 40 to $1000 \mathrm{mg} / \mathrm{kg}$ [55]. Soluble beta-glucans administration did not induce mortality, change in appearance or behavioural changes in mice or rats. In subsequent studies, mice and guinea pigs were injected intraperitoneally (i.p.) with beta-glucans $(250 \mathrm{mg} / \mathrm{kg})$ for seven consecutive days. The mice gained weight at the same rate as the saline-treated controls. However, guinea pigs receiving i.p. injections of soluble beta-glucans showed a significant $(p<0.05)$ 10-13\% decrease in weight gain over the 7-day period. No other toxicological, behavioural or appearance changes were noted.

To examine chronic toxicity, soluble beta-glucans were administered to mice twice weekly for a period of 30 or 60 days, at doses of 40, 200 or $1000 \mathrm{mg} / \mathrm{kg}$ [55]. No deaths were observed in any group. Chronic beta-glucans administration did not alter body weight, liver, lung or kidney weight. However, significant splenomegaly was observed in both the 30 and 60-day studies. Histopathological examination showed no tissue alterations at 40 or $200 \mathrm{mg} / \mathrm{kg}$. However, at $1000 \mathrm{mg} / \mathrm{kg}$, a mononuclear infiltrate was observed in the liver.

Pyrogenicity testing in New Zealand white rabbits revealed that parenteral beta-glucans administration $(5 \mathrm{mg} /$ 
$\mathrm{kg}$ ) did not significantly alter body temperature. The authors concluded that the systemic administration of soluble beta-glucans, over a wide dose range, does not induce mortality or significant toxicity in non-clinical studies [55].

\section{Beta-glucan levels in healthy subjects}

Beta-glucans, probably of dietary origin, are detectable in the serum of healthy individuals. Normal levels have been determined as $17 \mathrm{pg} / \mathrm{mL} \pm 34 \mathrm{pg} / \mathrm{mL}(0-51 \mathrm{pg} / \mathrm{mL})$ [61] and $10-40 \mathrm{pg} / \mathrm{mL}$ [4]. Raised levels are a marker of invasive fungal infections, and commercially available assays for beta-glucans are used diagnostically, typically in immunocompromised patients $[62,63]$. The serum of healthy humans also contains varying levels of anti-beta-glucan antibodies [64].

\section{Beta-glucan contamination of therapeutic products}

False-positive results of assays for beta-glucans (i.e. true elevations in serum beta-glucan levels but not due to invasive fungal infections) have been described for patients given blood, blood derivatives or broad-spectrum antibiotics, in patients with severe mucositis or bacteraemia, and in patients undergoing major surgery or extracorporeal purification techniques such as haemodialysis, haemofiltration or haemodiafiltration (reviewed in [65]). In patients undergoing renal replacement therapy, the false positives are thought to be due to beta-glucans released from the filters and membranes used in dialysis. Serum levels up to $5561 \mathrm{pg} / \mathrm{mL}$ have been described following a single dialysis session using cellulose-containing membranes (reviewed in [65]).

Cellulose-containing filters used to process blood products are also thought to be the source of elevated betaglucans levels in patients receiving blood products such as red blood cells, platelets or plasma products. Usami et al. detected beta-glucans contamination (defined as $>20 \mathrm{pg} /$ $\mathrm{mL}$ ) in $75 \%$ of albumin solutions, $40 \%$ of blood coagulation factors and $63 \%$ of immunoglobulin solutions tested [66]. Levels of beta-glucans as high as $7510 \mathrm{pg} / \mathrm{mL}$ were detected in these products. The authors estimated that plasma beta-glucans levels could reach $300 \mathrm{pg} / \mathrm{mL}$ after i.v. administration of $10 \mathrm{~g}$ of Gamma-Venin ${ }^{\circledR}$ (a brand of immunoglobulin used in Japan and other countries), high enough to lead to an incorrect diagnosis of invasive fungal infection. The total dose of beta-glucans administered with a $10 \mathrm{~g}$ dose of Gamma-Venin ${ }^{\circledR}$ was not provided. Of note, $10 \mathrm{~g}$ is within the range used for replacement of immunoglobulins in patients with hypogammaglobulinaemia
$(0.4-0.8 \mathrm{~g} / \mathrm{kg})$ but higher doses of immunoglobulin (1-2 g/ $\mathrm{kg}$, i.e. $70-140 \mathrm{~g}$ for a $70 \mathrm{~kg}$ adult) may be used in patients with diseases requiring immunomodulatory doses of immunoglobulins, such as immune thrombocytopenic purpura or Guillain-Barre syndrome.

In another study, high levels of beta-glucans were detected in the serum of patients 20 min after administration of various i.v. immunoglobulins and albumin [67]. The mean increases per $10 \mathrm{~g}$ of product \pm standard deviation were as follows: Intractect ${ }^{\circledR}, 1632 \pm 60 \mathrm{pg} / \mathrm{mL}$; Privigen ${ }^{\circledR}$, $300 \pm 91 \mathrm{pg} / \mathrm{mL} ;$ Octagam $^{\circledR}, 194 \pm 27 \mathrm{pg} / \mathrm{mL} ;$ Kiovig $^{\circledR}$, $119 \pm 22 \mathrm{pg} / \mathrm{mL}$; and albumin $20 \%, 156 \pm 32 \mathrm{pg} / \mathrm{mL}$. In a separate investigation, the authors also found what they described as "extraordinarily high" levels of beta-glucans in some patients who were recovering from Pneumocystis jirovecii infections (peak levels of $25,969 \mathrm{pg} / \mathrm{mL}$, interquartile range $15,070-33,540 \mathrm{pg} / \mathrm{mL}$ ) [67]. Since the patients were recovering from their illnesses, these findings could not be explained by the Pneumocystis jirovecii infection. As a result of this finding, the investigators considered that, although useful for diagnostic purposes, serum betaglucans levels were not a reliable indicator of recovery in patients with Pneumocystis jirovecii infection.

Beta-glucans have also been described in antibody products in development for potential administration to humans, notably those produced in yeast cells or cultured with yeast-derived additives [68].

\section{Soluble beta-glucans as a therapeutic agent}

Most recent publications relating to parenteral administration of soluble beta-glucans to humans have used lentinan, a form of beta-glucans extracted from shiitake mushrooms. Lentinan was approved in Japan in 1985 and in China in 1995, and it is widely used in these countries as an adjuvant to chemotherapy for patients with cancer. There appear to be at least six different formulations (of varying quality) available commercially (produced by five manufacturers) in China alone [69].

At least two other formulations of soluble beta-glucans have been developed for human use: a soluble beta-glucan from Biotec Pharmacon ASA, referred to simply as "SBG", and Imprime $\mathrm{PGG}^{\circledR}$ from Biothera Pharmaceuticals Inc. Trials of SBG appear to have completed recruitment but not been published (National Institutes of Health Clinical Trials identifiers NCT00533728 and NCT00533364). Imprime $\mathrm{PGG}^{\circledR}$, also known as PGG-beta-glucan or poly-(1-6)-beta-glucotriosyl-(1-3)-beta-glucopyranose, is described as a soluble pharmaceutical grade, yeast-derived 1,3/1,6 beta-glucan.

Despite widespread use in China and Japan, there is relatively little clinical data on i.v. beta-glucans use published 
in the English literature. Key clinical studies of lentinan and Imprime $\mathrm{PGG}^{\circledR}$ are summarised below.

\section{Lentinan}

Most publications relating to the use of lentinan are in Japanese (usually with an English abstract), and these indicate that lentinan can be given via the i.v. (most commonly), intraperitoneal, intrapleural [70-72] and intraarterial routes [73]. The commonest dose/schedule appears to be $2 \mathrm{mg}$ i.v. weekly, but i.v. doses as high as $10 \mathrm{mg}$ have been given (see [6] for example). In addition, there are several ongoing Japanese phase II trials in patients with advanced gastric cancer (Trial identifiers in the World Health Organisation meta-register of clinical trials: JPRN-UMIN000010724, JPRN-UMIN000008590, JPRN-UMIN000007726 and JPRN-UMIN000001913). In these trials, where specified, lentinan is given i.v. at a dose of $2 \mathrm{mg}$ weekly in combination with chemotherapy (TS-1, with or without cisplatin). A randomised phase III study of TS-1 alone versus TS-1 plus lentinan in advanced or recurrent gastric cancer appears to be complete but not published in the English literature. In this study, lentinan was given i.v. weekly but the dose is not specified.

The pharmacokinetics of lentinan given i.v. over $2 \mathrm{~h}$ at doses of 1,2 or $4 \mathrm{mg}$, have been evaluated in healthy volunteers and gastric cancer patients [74]. After $1 \mathrm{mg}$ of lentinan, plasma concentrations reached a maximum at the end of infusion $(51-73 \mathrm{ng} / \mathrm{mL}$ ) and decreased gradually thereafter. In healthy volunteers, lentinan concentrations $24 \mathrm{~h}$ after administration were (mean $\pm \mathrm{SD}$ ) $71 \pm 21 \mathrm{ng} / \mathrm{mL}$ after a $4 \mathrm{mg}$ dose, and $53 \pm 11 \mathrm{ng} / \mathrm{mL}$ after a $2 \mathrm{mg}$ dose. In three patients given $1 \mathrm{mg}$, levels were around $10-20 \mathrm{ng} / \mathrm{mL}$ after $24 \mathrm{~h}$. Thereafter, levels declined slowly over approximately 7 days until they reached the detection limit. The pharmacokinetics of i.v. lentinan in humans were similar to those in the rat. Lentinan was found to be stable in human plasma, and the decline in plasma levels was thought to be due to uptake or degradation in cells, probably Kupffer cells in the liver.

In phase I/II placebo-controlled studies, HIV-positive patients were given 2, 5 or $10 \mathrm{mg}$ of lentinan (or placebo) i.v. over $10 \mathrm{~min}$ once a week for 8 weeks, or $1 \mathrm{or} 5 \mathrm{mg}$ of lentinan i.v. over 30 min twice a week for 12 weeks [6]. Side effects were mainly mild, especially when the infusion was carried out over a 30-min period. When the infusion was over a 30-min period, there were no severe side effects and only four dropouts due to toxicity or patient preference. However, when administration was over a 10-min period, severe side effects occurred (one case each of anaphylactoid reaction, back pain, leg pain, depression, rigor, fever, chills, granulocytopenia and elevated liver enzymes) and four patients discontinued therapy as a result. Other investigators have also linked the side effects of lentinan (such as "oppression in the anterior chest" and dryness of the throat) to rapid infusions [7].
An individual patient-based meta-analysis of randomised trials of lentinan in gastric cancer included 650 patients from five trials of chemotherapy (combinations of S-1, mitomycin C and cisplatin), with or without lentinan (2 mg i.v. weekly) [75]. The concurrent use of lentinan with chemotherapy was found to significantly prolong overall survival compared with chemotherapy alone (hazard ratio 0.80; $95 \%$ confidence intervals [CI] 0.68-0.95; stratified $\log$ rank $p=0.011$ ). No major differences in haematological or non-haematological adverse events were reported for the two treatment regimens, although leucopenia was reported in $5.6 \%$ of patients receiving chemotherapy plus lentinan versus $1.6 \%$ of patients receiving chemotherapy alone. A meta-analysis has also been published of randomised chemotherapy trials, with or without lentinan, in non-small cell lung cancer (NSCLC) [76]. All the trials were conducted in China and published in Chinese. The addition of lentinan to chemotherapy resulted in higher response rates (relative risk $[R R]=1.31,95 \% \mathrm{CI}$ 1.14-1.52) with less frequent Grade 3-4 gastrointestinal toxicity $(\mathrm{RR}=0.54,95 \% \mathrm{CI} 0.43-0.68)$ and Grade 3-4 granulocytopenia $(\mathrm{RR}=0.65,95 \% \mathrm{CI} 0.51-0.70)$ than with chemotherapy alone.

A randomised phase II trial published since the gastric cancer meta-analysis included 78 patients with advanced gastric cancer who received S1-based chemotherapy as first line treatment, with or without lentinan $(2 \mathrm{mg}$ i.v. every 2 or 3 weeks) [77]. Median overall survival was significantly longer in the lentinan group than in the chemotherapy alone group (689 days [95 \% CI 431-2339 days] versus 565 days [95\% CI 323-662 days]; $p=0.0406$ ). The most frequently observed severe (Grade 3-4) toxicity was neutropenia (chemo-immunotherapy $50 \%$, chemotherapy alone $45 \%$ ) but Grade 3 febrile neutropenia was only observed in one patient in each group. There were essentially no differences in the incidence or severity of adverse effects between patients who did and those who did not receive lentinan. Administration of lentinan was observed to suppress the granulocyte:lymphocyte ratio.

As described earlier, a $500 \mathrm{ng}$ dose of beta-glucans could in theory be co-administered with a single dose of our product. In comparison, the maximum dose of i.v. lentinan used in routine practice or clinical trials is $10 \mathrm{mg}$, representing a safety margin of 1:20,000. From the study published by Yajima et al. [74], a $1 \mathrm{mg}$ dose of lentinan given over $2 \mathrm{~h}$ resulted in a maximum plasma concentration of $73 \mathrm{ng} / \mathrm{mL}$ in patients with gastric cancer, indicating initial rapid clearance (since without any clearance the plasma concentration should have been around $200 \mathrm{ng} / \mathrm{mL}$, based on a $5 \mathrm{~L}$ estimated blood volume). Extrapolating from these data suggests that a $500 \mathrm{ng}$ dose of beta-glucans given over $2 \mathrm{~h}$ would only increase plasma levels to approximately $37 \mathrm{pg} / \mathrm{mL}$, well within normal physiological levels of $17 \mathrm{pg} / \mathrm{mL} \pm 34 \mathrm{pg} / \mathrm{mL}$. 


\section{Imprime PGG ${ }^{\circledR}$}

Imprime $\mathrm{PGG}^{\circledR}$ has been evaluated in a range of clinical trials [78]. These indicate that Imprime PGG ${ }^{\circledR}$ can be given i.v. at doses of $4 \mathrm{mg} / \mathrm{kg}$ weekly, and as single doses up to $6 \mathrm{mg} / \mathrm{kg}$ (for a $70 \mathrm{~kg}$ adult, this would equate to a $420 \mathrm{mg}$ dose). Typical systemic clearance of beta-glucan in healthy subjects and cancer patients treated with Imprime $\mathrm{PGG}^{\circledR}$ and cetuximab (with or without chemotherapy) were 0.491 , 0.565 , and $0.690 \mathrm{~L} / \mathrm{h}$, respectively [79]. The effective half-life of beta-glucan ranged from 19.5 to $27.3 \mathrm{~h}$. In one study, mean area under the curve over $24 \mathrm{~h}$ of beta-glucan in Cycle 1 was similar to that in Cycle 3 (362 and $383 \mu \mathrm{g}$. $\mathrm{hr} / \mathrm{mL}$, respectively) [80]. Likewise, mean peak concentrations of beta-glucan in Cycles 1 and 3 were similar (44.3 and $47.8 \mu \mathrm{g} / \mathrm{mL}$, respectively). Minimal accumulation of beta-glucan was observed with trough concentrations on Day 1 Cycle 2 and Day 1 Cycle 3 of 0.0680 and $0.117 \mu \mathrm{g} /$ $\mathrm{mL}$, respectively.

Detailed safety data are available from a randomised phase II study $(n=89)$ of paclitaxel, carboplatin and bevacizumab with or without Imprime $\mathrm{PGG}^{\circledR}(4 \mathrm{mg} / \mathrm{kg}$ weekly) in patients with previously untreated NSCLC [81]. Events potentially associated with hypersensitivity reactions occurred more frequently with Imprime $\mathrm{PGG}^{\circledR}$, including one Grade 3 anaphylactic reaction. As a result, the authors recommend premedication with low dose corticosteroids and anti-histamines prior to Imprime PGG $^{\circledR}$ administration. Of interest, overall and Grade 3-4 infections were less frequently reported in the Imprime $\mathrm{PGG}^{\circledR}$ group compared to control (47.5\% vs $63.3 \%$ overall; $5.1 \%$ vs $10.0 \%$ Grade 3-4). Immune-mediated adverse events (e.g. immune-mediated hepatitis or endocrinopathies) that are reported with $\mathrm{T}$ cell modulators (such as ipilimumab) were not observed with Imprime PGG $^{\circledR}$. Higher response rates, longer duration of response and improved survival were also reported for patients in the Imprime PGG $^{\circledR}$ group, although the study was not powered to demonstrate statistically significant improvements in these parameters.

Similar results were reported for a randomised phase II $(n=90)$ trial of Imprime PGG $^{\circledR}$ in combination with paclitaxel, carboplatin and cetuximab in NSCLC [82]. Overall (all grades) and Grade 3-4 adverse events potentially associated with hypersensitivity or infusion reactions were not increased in the Imprime PGG ${ }^{\circledR}$ treatment arm in this study, but infections were less frequently reported (an absolute difference of $5 \%$ between the two treatment groups). Immune-mediated adverse events (e.g. endocrinopathies) were not observed with Imprime $\mathrm{PGG}^{\circledR}$. Higher response rates were reported in patients who received Imprime $\mathrm{PGG}^{\circledR}$ in addition to standard therapy, especially in patients with higher levels of pre-existing anti-beta-glucans antibody levels, although time-to-event outcomes were balanced between the two groups.
Ongoing trials of Imprime $\mathrm{PGG}^{\circledR}$ include a large $(n=795)$ randomised phase III trial in combination with cetuximab in patients with advanced KRAS wild-type colorectal cancer (NCT01309126). This trial started in April 2011 and is expected to complete in 2016. Other ongoing trials include a phase I/II trial of Imprime $\mathrm{PGG}^{\circledR}$ in combination with rituximab in patients with indolent nonHodgkin lymphoma (NCT02086175). A phase I/II trial of Imprime $\mathrm{PGG}^{\circledR}$ in combination with an antibody and gemcitabine in pancreatic cancer was terminated early due to a drug recall (drug not specified) (NCT02132403).

The usual dose of Imprime PGG ${ }^{\circledR}$ used in clinical trials is $4 \mathrm{mg} / \mathrm{kg}$ ( $280 \mathrm{mg}$ for a $70 \mathrm{~kg}$ adult), 560,000 times higher than the maximum dose of beta-glucans $(500 \mathrm{ng})$ that could be theoretically be administered with our product.

\section{Discussion and conclusions}

Overall, potential administration of up to $500 \mathrm{ng}$ of soluble beta-glucans as a contaminant of a biotherapeutic product is not considered a safety concern in view of the very much larger doses of soluble beta-glucans (lentinan, Imprime PGG $^{\circledR}$ and others) administered to humans i.v, the levels found in blood products and associated with dialysis, and reassuring preclinical studies. Both preclinical and clinical data indicate that beta-glucans are well tolerated, regardless of the route of administration. Doses as high as $4 \mathrm{mg} /$ $\mathrm{kg}$ (approximately 560,000 times higher than $500 \mathrm{ng}$ ) have been repeatedly administered to humans i.v., without apparent ill-effects. Since biological agents such as monoclonal antibodies are generally administered by infusion over one to several hours, the chances of acute adverse effects due to beta-glucans contamination are further reduced; these effects appear to be mainly associated with rapid (10 $\mathrm{min}$ ) infusions of lentinan (with doses of $1 \mathrm{mg}$ or greater). Accordingly, a limit of $10 \mathrm{ng} / \mathrm{mg}$ (or $500 \mathrm{ng}$ total dose) of beta-glucans is considered to pose a low risk to patients, and this specification was acceptable to the Medicines and Healthcare Products Regulatory Agency for our product. From a safety perspective, this level is probably considerably more stringent than necessary since it provides a very broad safety margin.

Much less is known about the levels at which the immunostimulatory effects of beta-glucans might occur. There is a dearth of clinical data in the English literature for doses lower than $2 \mathrm{mg} /$ patient (the lowest dose commonly investigated in clinical efficacy trials of lentinan). However, in vitro studies suggest that significant immunostimulatory effects are unlikely to occur at serum beta-glucans concentrations lower than $1 \mathrm{ng} / \mathrm{mL}(1000 \mathrm{pg} / \mathrm{mL})$, a concentration 10 times greater than the highest concentration likely to be encountered in our trial, especially with transient exposure. Most anti-tumour effects of beta-glucans appear to be mediated indirectly by its 
immunostimulatory properties. Although direct anti-proliferative and pro-apoptotic effects have been described, these appear to require higher concentrations of beta-glucans.

In patients with cancer (the intended patient population for the CRUKD/14/001 trial), possible immunostimulatory and/or direct anti-tumour effects of beta-glucan contaminants would, if anything, be considered desirable from a patient benefit perspective. However, in this first-in man, first-in-class, proof-of-concept trial, it is important to ensure that any anti-tumour efficacy observed is due to therapeutic MOv18 IgE itself. Moreover, for biotherapeutic agents developed for non-oncology indications, immunostimulatory effects would not necessarily be desirable. Based on currently available data, a limit of $10 \mathrm{ng} / \mathrm{mg}$ (or $500 \mathrm{ng}$ total dose) of beta-glucans seems unlikely to provoke any clinically significant immunological effects and this level may be acceptable for medicinal agents.

Funding The authors acknowledge support by Cancer Research UK (CRUK) (C30122/A11527; C30122/A15774); The Academy of Medical Sciences; the Medical Research Council (MR/L023091/1); CRUK/National Institute for Health Research (NIHR) in England/ Department of Health for Scotland, Wales and Northern Ireland Experimental Cancer Medicine Centre (C10355/A15587). The research was supported by the NIHR Biomedical Research Centre based at Guy's and St Thomas' National Health Service Foundation Trust and King's College London. The views expressed are those of the authors and not necessarily those of the National Health Service, the NIHR or the Department of Health.

\section{Compliance with ethical standards}

Conflict of interest Claire Barton is a freelance pharmaceutical physician/medical advisor with Barton Oncology Ltd and in the last 5 years has undertaken consultancy work with Roche Products Ltd, Cancer Research UK Centre for Drug Development, Wellcome Trust Ltd, SFL Services GmBH, Mosaic Biomedicals SL, Alacrita LLP, Astex Therapeutics Ltd, BerGen Bio A/S, EngMab AG, Inbiomotion SL, Michelangelo Foundation, Norgine Pharmaceuticals Ltd, Ono Pharma UK Ltd, Piqur Therapeutics AG, and Shionogi Ltd. Claire Barton is on the advisory board for SFL Services GmBH and owns shares in GlaxoSmithKline. All other authors declare they have no conflict of interest.

Open Access This article is distributed under the terms of the Creative Commons Attribution 4.0 International License (http://creativecommons.org/licenses/by/4.0/), which permits unrestricted use, distribution, and reproduction in any medium, provided you give appropriate credit to the original author(s) and the source, provide a link to the Creative Commons license, and indicate if changes were made.

\section{References}

1. Barsanti L, Passarelli V, Evangelista V, Frassanito AM, Gualtieri P (2011) Chemistry, physico-chemistry and applications linked to biological activities of $\beta$-glucans. Nat Prod Rep 28(3):457-466

2. No author: ICH Q6A Specifications: Test Procedures and Acceptance Criteria for New Drugs Substances and New Drug
Products: Chemical Substances, October 1999: http://www.ich. org/fileadmin/Public_Web_Site/ICH_Products/Guidelines/Quality/Q6A/Step4/Q6Astep4.pdf Accessed 22 May 2016

3. No author: ICH Q6B Specifications: test procedures and acceptance criteria for biotechnological/biological products, March 1999: http://www.ich.org/fileadmin/Public_Web_Site/ICH_Products/Guidelines/Quality/Q6B/Step4/Q6B_Guideline.pdf Accessed 22 May 2016

4. Sandle T (2013) Pharmaceutical product impurities: considering beta glucans. Review of American Pharmaceutical Business \& Technology 16 (5). Posted 31 http://www.americanpharmaceuticalreview.com/Featured-Articles/152953-Pharmaceutical-Product-Impurities-Considering-Beta-Glucans/

5. Rudman SM, Josephs DH, Cambrook H et al (2011) Harnessing engineered antibodies of the IgE class to combat malignancy: initial assessment of Fc epsilonRI-mediated basophil activation by a tumour-specific IgE antibody to evaluate the risk of type I hypersensitivity. Clin Exp Allergy 41(10):1400-1413

6. Gordon M, Bihari B, Goosby E, Gorter R, Greco M, Guralnik M, Mimura T, Rudinicki V, Wong R, Kaneko Y (1998) A placebocontrolled trial of the immune modulator, lentinan, in HIV-positive patients: a phase I/II trial. J Med 29(5-6):305-330

7. Wada T, Nishide T, Hatayama K et al (1987) A comparative clinical trial with tegafur plus lentinan treatment at two different doses in advanced cancer. Gan To Kagaku Ryoho 14(8):25092512 (Article in Japanese with English abstract)

8. Karagiannis SN, Wang Q, Burke F, Riffard S, Bracher MG, Thompson RG, Durham SR, Schwartz LB, Balkwill FR, Gould HJ (2003) Activity of human monocytes in IgE antibodydependent surveillance and killing of ovarian tumor cells. Eur $\mathbf{J}$ Immunol 33(4): 1030-1040

9. Karagiannis SN, Bracher MG, Hunt J et al (2007) IgE-antibodydependent immunotherapy of solid tumors: cytotoxic and phagocytic mechanisms of eradication of ovarian cancer cells. J Immunol 179(5):2832-2843

10. Karagiannis SN, Bracher MG, Beavil RL (2008) The role of IgE receptors in IgE antibody-dependent cytotoxicity and phagocytosis of ovarian tumor cells by human monocytic cells. Cancer Immunol Immunother 57(2):247-263

11. Josephs DH, Spicer JF, Karagiannis P, Gould HJ, Karagiannis SN (2014) IgE immunotherapy a novel concept with promise for the treatment of cancer. mAbs 6(1):54-72

12. Josephs DH, Bax HJ, Lentfer H, Selkirk C, Spicer JF, Karagiannis SN (2015) Potential for monocyte recruitment by IgE immunotherapy for cancer in a rat model of tumour metastasis. Lancet 385(Suppl 1):S53. doi:10.1016/S0140-6736(15)60368-3

13. Vigor K, Emerson J, Scott R, Cheek J, Barton C, Bax HJ, Josephs DH, Karagiannis SN, Spicer JF, Lentfer H. Development of downstream processing to minimise beta-glucan impurities in GMP-manufactured therapeutic antibodies. (Submitted to Biotechnol Prog)

14. Whitehead A, Beck EJ, Tosh S, Wolever TM (2014) Cholesterollowering effects of oat $\beta$-glucan: a meta-analysis of randomized controlled trials. Am J Clin Nutr 100(6):1413-1421

15. Othman RA, Moghadasian MH, Jones PJ (2011) Cholesterollowering effects of oat $\beta$-glucan. Nutr Rev 69(6):299-309

16. Chen J, Raymond K (2008) Beta-glucans in the treatment of diabetes and associated cardiovascular risks. Vasc Health Risk Manag 4(6):1265-1272 (Review)

17. Andersson KE, Hellstrand P (2012) Dietary oats and modulation of atherogenic pathways. Mol Nutr Food Res 56(7):1003-1013 (Review)

18. Schwartz B, Hadar Y (2014) Possible mechanisms of action of mushroom-derived glucans on inflammatory bowel disease and associated cancer. Ann Transl Med 2(2):19

19. Amazon search for "beta glucan": https://www.amazon.co.uk/s/ ref=nb_sb_noss_1?url=search-alias\%3Daps\&field-keywords= 
beta + glucan\&rh $=\mathrm{i} \% 3$ Aaps $\% 2 \mathrm{Ck} \% 3$ Abeta + glucan Accessed 8 July 2016

20. Web MD website: http://www.webmd.com/vitamins-supplements/ingredientmono-1041-beta\%20glucans.aspx?activeingred ientid $=1041 \&$ activeingredientname $=$ beta $\% 20$ glucans Accessed 22 May 2016

21. Du B, Bian Z, Xu B (2014) Skin health promotion effects of natural beta-glucan derived from cereals and microorganisms: a review. Phytother Res 28(2):159-166 (Review)

22. Goodridge HS, Wolf AJ, Underhill DM (2009) Beta-glucan recognition by the innate immune system. Immunol Rev 230:38-50

23. Chan GC, Chan WK, Sze DM (2009) The effects of beta-glucan on human immune and cancer cells. J Hematol Oncol 2:25

24. Kim HS, Hong Jin Tae, Kim Youngsoo, Han Sang-Bae (2011) Stimulatory effect of $\beta$-glucans on immune cells. Immune Netw 11(4):191-195

25. Li X, Wang Jing, Wang Wei et al (2013) Immunomodulatory activity of a novel, synthetic beta-glucan ( $\beta$-glu6) in murine macrophages and human peripheral blood mononuclear cells. PLoS ONE 8(11):e80399

26. Vannucci L, Krizan J, Sima P, Stakheev D, Caja F, Rajsiglova L, Horak V, Saieh M (2013) Immunostimulatory properties and antitumor activities of glucans (Review). Int J Oncol 43(2):357-364

27. Jesenak M, Banovcin P, Rennerova Z, Majtan J (2014) $\beta$-Glucans in the treatment and prevention of allergic diseases. Allergol Immunopathol (Madr) 42(2):149-156

28. Edwards JE Jr (2012) Fungal cell wall vaccines: an update. J Med Microbiol 61(Pt 7):895-903

29. Huang H, Ostroff GR, Lee CK, Specht CA, Levitz SM (2013) Characterization and optimization of the glucan particle-based vaccine platform. Clin Vaccine Immunol 20(10):1585-1591

30. Liu M, Luo F, Ding C, Albeituni S, Hu X, Ma Y, Cai Y, McNally L, Sanders MA, Jain D, Kloecker G, Bousamra M 2nd, Zhang HG, Higashi RM, Lane AN, Fan TW, Yan J (2015) Dectin-1 activation by a natural product $\beta$-glucan converts immunosuppressive macrophages into an M1-like phenotype. J Immunol 195(10):5055-5065

31. Baran J, Allendorf DJ, Hong F, Ross GD (2007) Oral betaglucan adjuvant therapy converts nonprotective Th2 response to protective Th1 cell-mediated immune response in mammary tumor-bearing mice. Folia Histochem Cytobiol 45(2):107-114

32. Tian J, Ma J, Ma K, Guo H, Baidoo SE, Zhang Y, Yan J, Lu L, Xu H, Wang S (2013) $\beta$ Glucan enhances antitumor immune responses by regulating differentiation and function of monocytic myeloid-derived suppressor cells. Eur J Immunol 43(5):1220-1230

33. Ning Y, Xu D, Zhang X, Bai Y, Ding J, Feng T, Wang S, Xu N, Qian K, Wang Y, Qi C (2016) $\beta$-glucan restores tumor-educated dendritic cell maturation to enhance antitumor immune responses. Int J Cancer 138(11):2713-2723

34. Li B, Cai Y, Qi C, Hansen R, Ding C, Mitchell TC, Yan J (2010) Orally administered particulate beta-glucan modulates tumorcapturing dendritic cells and improves antitumor T-cell responses in cancer. Clin Cancer Res 16(21):5153-5164

35. Hunter KW Jr, DuPre' S, Redelman D (2004) Microparticulate beta-glucan upregulates the expression of B7.1, B7.2, B7-H1, but not B7-DC on cultured murine peritoneal macrophages. Immunol Lett 93(1):71-78

36. Hong F, Hansen RD, Yan J, Allendorf DJ, Baran JT, Ostroff GR, Ross GD (2003) Beta-glucan functions as an adjuvant for monoclonal antibody immunotherapy by recruiting tumoricidal granulocytes as killer cells. Cancer Res 63(24):9023-9031

37. Allendorf DJ, Yan J, Ross GD, Hansen RD, Baran JT, Subbarao K, Wang L, Haribabu B (2005) C5a-mediated leukotriene B4-amplified neutrophil chemotaxis is essential in tumor immunotherapy facilitated by anti-tumor monoclonal antibody and beta-glucan. J Immunol 174(11):7050-7056

38. Segal NH, Gada P, Senzer N, Gargano MA, Patchen ML, Saltz LB (2016) A Phase II efficacy and safety, open-label, multicenter study of Imprime PGG injection in combination with cetuximab in patients with Stage IV KRAS-mutant colorectal cancer. Clin Colorectal Cancer. doi:10.1016/j.clcc.2016.02.013

39. Modak S, Kushner BH, Kramer K, Vickers A, Cheung IY, Cheung NK (2013) Anti-GD2 antibody 3F8 and barleyderived $(1 \rightarrow 3),(1 \rightarrow 4)-\beta-<i>D</ i>$-glucan: a Phase I study in patients with chemoresistant neuroblastoma. Oncoimmunology 2(3):e23402

40. Zent CS, Call TG, Bowen DA, Conte MJ, LaPlant BR, Witzig TE, Ansell SM, Weiner GJ (2015) Early treatment of high risk chronic lymphocytic leukemia with alemtuzumab, rituximab and poly-(1-6)-beta-glucotriosyl-(1-3)- beta-glucopyranose beta-glucan is well tolerated and achieves high complete remission rates. Leuk Lymphoma 56(8):2373-2378

41. Higashi T, Hashimoto K, Takagi R, Mizuno Y, Okazaki Y, Tanaka Y et al (2010) Curdlan induces DC-mediated Th17 polarization via Jagged1 activation in human dendritic cells. Allergol Int 59:161-166

42. Yoon TJ, Kim TJ, Lee H, Shin KS, Yun YP, Moon WK, Kim DW, Lee KH (2008) Anti-tumor metastatic activity of beta-glucan purified from mutated Saccharomyces cerevisiae. Int Immunopharmacol 8:36-42

43. Wakshull E, Brunke-Reese D, Lindermuth J, Fisette L, Nathans RS, Crowley JJ, Tufts JC, Zimmerman J, Mackin W, Adams DS (1999) PGG-glucan, a soluble beta-(1,3)-glucan, enhances the oxidative burst response, microbicidal activity and activates an NF-kappa B-like factor in human PMN: evidence for a glycosphingolipid beta-(1, 3)-glucan receptor. Immunopharmacology 41:89-107

44. Lin YL, Liang YC, Lee SS, Chiang BL (2005) Polysaccharide purified from Ganoderma lucidum induced activation and maturation of human monocyte-derived dendritic cells by the NFkappaB and p38 mitogen-activated protein kinase pathways. J Leukoc Biol 78(2):533-543

45. Chan WK, Law HK, Lin ZB, Lau YL, Chan GC (2007) Response of human dendritic cells to different immunomodulatory polysaccharides derived from mushroom and barley. Int Immunol 19(7):891-899

46. Doita M, Rasmussen LT, Seljelid R, Lipsky PE (1991) Effect of soluble aminated beta-1,3-D-polyglucose on human monocytes: stimulation of cytokine and prostaglandin E2 production but not antigen-presenting function. J Leukoc Biol 49:342-351

47. Sato T, Iwabuchi K, Nagaoka I et al (2006) Induction of human neutrophil chemotaxis by Candida albicans-derived beta-1,6long glycoside side-chain-branched beta-glucan. J Leukoc Biol 80(1):204-211

48. Holck P, Sletmoen M, Torget Stokke B, Permin H, Norn S (2007) Potentiation of histamine release by microfungal $(1 \rightarrow 3)$ - and $(1 \rightarrow 6)-\beta$-D-glucans. Basic Clin Pharmacol Toxicol 101:455-458

49. Morikawa K, Takeda R, Yamazaki M, Mizuno D (1985) Induction of tumoricidal activity of polymorphonuclear leukocytes by a linear beta-1, 3-D-glucan and other immunomodulators in murine cells. Cancer Res 45(4):1496-1501

50. Chanput W, Reitsma M, Kleinjans L, Mes JJ, Savelkoul HF, Wichers HJ (2012) $\beta$-glucans are involved in immune-modulation of THP-1 macrophages. Mol Nutr Food Res 56:822-833

51. Berovic M, Habijanic J, Zore I, Wraber B, Hodzar D, Boh B, Pohleven F (2003) Submerged cultivation of Ganoderma lucidum biomass and immunostimulatory effects of fungal polysaccharides. J Biotecnol 103:77-86

52. Youn MJ, Kim JK, Park SY, Kim Y, Park C, Kim ES, Park KI, So HS, Park R (2009) Potential anticancer properties of the water 
extract of Inonotus [corrected] obliquus by induction of apoptosis in melanoma B16-F10 cells. J Ethnopharmacol 121:221-228

53. Chen W, Zhao Z, Chen SF et al (2008) Optimization for the production of exopolysaccharide from Fomes fomentarius in submerged culture and its antitumor effect in vitro. Bioresour Technol 99:3187-3194

54. Zhang M, Chiu LC, Cheung PC, Ooi VE (2006) Growth-inhibitory effects of a beta-glucan from the mycelium of Poria cocos on human breast carcinoma MCF-7 cells: cell-cycle arrest and apoptosis induction. Oncol Rep 15:637-643

55. Williams DL, Sherwood ER, Browder IW, McNamee RB, Jones EL, Di Luzio NR (1988) Pre-clinical safety evaluation of soluble glucan. Int J Immunopharmacol 10(4):405-414

56. Pretus HA, Ensley HE, McNamee RB, Jones EL, Browder IW, Williams DL (1991) Isolation, physicochemical characterization and preclinical efficacy evaluation of soluble scleroglucan. $\mathbf{J}$ Pharmacol Exp Ther 257(1):500-510

57. Lee JN, Lee DY, Ji IH, Kim GE, Kim HN, Sohn J, Kim S, Kim CW (2001) Purification of soluble beta-glucan with immuneenhancing activity from the cell wall of yeast. Biosci Biotechnol Biochem 65(4):837-841

58. Browder W, Rakinic J, McNamee R, Jones E, Williams D, Di Luzio N (1983) Protective effect of nonspecific immunostimulation in postsplenectomy sepsis. J Surg Res 35(6):474-479

59. Browder IW, Williams DL, Kitahama A, Di Luzio NR (1984) Modification of post-operative C. albicans sepsis by glucan immunostimulation. Int J Immunopharmacol 6(1):19-26

60. Browder W, Williams D, Sherwood E, McNamee R, Jones E, DiLuzio N (1987) Synergistic effect of nonspecific immunostimulation and antibiotics in experimental peritonitis. Surgery 102(2):206-214

61. Odabasi Z, Mattiuzzi G, Estey E, Kantarjian H, Saeki F, Ridge RJ, Ketchum PA, Finkelman MA, Rex JH, Ostrosky-Zeichner L (2004) Beta-D-glucan as a diagnostic adjunct for invasive fungal infections: validation, cutoff development, and performance in patients with acute myelogenous leukemia and myelodysplastic syndrome. Clin Infect Dis 39(2):199-205

62. Lamoth F, Cruciani M, Mengoli C et al (2012). Beta-glucan antigenemia assay for the diagnosis of invasive fungal infections in patients with hematological malignancies: a systematic review and meta-analysis of cohort studies from the Third European Conference on Infections in Leukemia (ECIL-3). Clin Infect Dis 54:633-643

63. Karageorgopoulos DE, Vouloumanou EK, Ntziora F et al (2011) $\beta$-D-glucan assay for the diagnosis of invasive fungal infections: a meta-analysis. Clin Infect Dis 52(6):750-770

64. Noss I, Wouters IM, Smit LA, Meijer E, Pronk A, Heederik DJ, Doekes G (2012) IgG to various $\beta$-glucans in a human adult population. Int Arch Allergy Immunol 157(1):98-108

65. Prattes J, Schilcher G, Krause R (2015) Reliability of serum 1,3-beta-D-glucan assay in patients undergoing renal replacement therapy: a review of the literature. Mycoses 58(1):4-9

66. Usami M, Ohata A, Horiuchi T, Nagasawa K, Wakabayashi T, Tanaka $S$ (2002) Positive $(1 \rightarrow 3)-\beta$-D- glucan in blood components and release of $(1 \rightarrow 3)-\beta$-D-glucan from depth-type membrane filters for blood processing. Transfusion 42:1189-1195

67. Held J, Wagner D (2011) Beta-d-glucan kinetics for the assessment of treatment response in Pneumocystis jirovecii pneumonia. Clin Microbiol Infect 17:1118-1122

68. Wang F, Li H, Chen $\mathrm{Z}$ et al (2014) Demonstrating $\beta$-glucan clearance in $\mathrm{CHO}$ - and yeast-produced monoclonal antibodies during downstream purification processes. J Bioprocess Biotech 4:185

69. Chen YW, Hua DJ, Cheonga KL et al (2013) Quality evaluation of lentinan injection produced in China. J Pharm Biomed Anal 78-79:176-182
70. Yoshino S, Oka M, Hazama S, Suzuki T (1990) Effect of intrapleural and/or intraperitoneal lentinan therapy in carcinomatous pleuritis and peritonitis. Gan To Kagaku Ryoho 17(8 Pt 2):15881591 (Article in Japanese with English abstract)

71. Oka M, Yoshino S, Hazama S, Shimoda K, Suzuki T (1992) Immunological analysis and clinical effects of intraabdominal and intrapleural injection of lentinan for malignant ascites and pleural effusion. Biotherapy 5(2):107-112 (Article in Japanese with English abstract)

72. Hazama S, Oka M, Yoshino S et al (1995) Clinical effects and immunological analysis of intraabdominal and intrapleural injection of lentinan for malignant ascites and pleural effusion of gastric carcinoma. Gan To Kagaku Ryoho 22(11):1595-1597 (Article in Japanese with English abstract)

73. Okuyama K, Isono K, Satoh H et al (1982) Effect of continuous intra-arterial infusion therapy with BLM-MMC-lentinan (B-M$\mathrm{L}$ ) in treating patients with hepatic metastases of esophageal cancer. Nihon Gan Chiryo Gakkai Shi 17(7):1895-1901 (Japanese. No abstract available)

74. Yajima Y, Satoh J, Fukuda I et al (1989) Quantitative assay of lentinan in human blood with the limulus colorimetric test. Tohoku J Exp Med 157:145-151

75. Oba K, Kobayashi M, Matsui $T$ et al (2009) Individual patient based meta-analysis of lentinan for unresectable/recurrent gastric cancer. Anticancer Res 29:2739-2746

76. Yin X, Ying J, Li L, Zhang H, Wang H (2015) A meta-analysis of lentinan injection combined with chemotherapy in the treatment of nonsmall cell lung cancer. Indian $\mathrm{J}$ Cancer 52(Suppl):E29-E31

77. Ina K, Furuta R, Kataoka $T$ et al (2011) Lentinan prolonged survival in patients with gastric cancer receiving $\mathrm{S}$-1-based chemotherapy. World J Clin Oncol 2(10):339-343

78. Biothera company website (published data on Imprime PGG): http://www.biothera.com/technology/papers-and-presentations/ Accessed 2 June 2015

79. Marier JF, Menard AL, Beliveau M et al (2014). Modelling and simulations of $\beta$-glucan after administration of PGG-glucan alone or in combination with cetuximab, with and without irinotecan, in colorectal cancer patients. American Society for Clinical Pharmacology and Therapeutics, Atlanta, GA March 2014 (abstract) (abstract available on Biothera company website: http://www.biothera.com/technology/papers-and-presentations/ modeling-and-simulations-of-\%CE\% B2-glucan-after-administration-of-pgg-glucan-alone/Accessed 2 June 2015)

80. Marier JF, Jomphe C, Beliveau M et al (2014). Pharmacokinetic analysis of $\beta-$ glucan following administration of Imprime PGG, a novel $\beta$-glucan immunomodulator being developed for the treatment of non-small cell lung cancer. American Society for Clinical Pharmacology and Therapeutics, Atlanta, GA, March 2014 (abstract) (poster available on Biothera company website; http://www.biothera.com/ technology/papers-and-presentations/Accessed 2 June 2015)

81. Braun A, Engel-Riedel W, Wolf M et al (2015). Efficacy and safety of Imprime PGG, a novel innate immune modulator, in combination with bevacizumab (Bev), carboplatin and paclitaxel, in the 1st-line treatment of stage IV NSCLC. European Lung Cancer Conference 15-18 April 2015, abstract 112p (poster available on Biothera company website; http://www.biothera.com/ technology/papers-and-presentations/Accessed 2 June 2015)

82. Schneller F, Thomas M, Sajadian P et al (2014). Chemoimmunotherapy of advanced non-small cell lung cancer with Imprime PGG in combination with cetuximab, carboplatin and paclitaxel - analysis of secondary endpoints of a multicenter randomized phase 2 trial. Ann Oncol (2014) 25 (suppl 4): iv369 (abstract 1071p) (poster available on Biothera company website; http:// www.biothera.com/technology/papers-and-presentations/ Accessed 2 June 2015) 